\title{
Effect of the bacterium Serratia marcescens SCBI on the longevity and reproduction of the nematode Caenorhabditis briggsae KT0001
}

\author{
Jeremiah D Lancaster, Budour Mohammad and Eyualem Abebe*
}

\begin{abstract}
Background: Extensive research effort has advanced our understanding of Caenorhabditis as a model system, but its natural association with bacteria remains to be explored in an ecological context. Explored associations vary vastly from mutualistic to parasitic. Serratia marcescens has been shown to be pathogenic to Caenorhabditis with a fitness cost. The recent isolation of an entomopathogenic Caenorhabditis briggsae KT0001/S. marcescens SCBI association from the wild has allowed us to examine under laboratory conditions whether such an association poses a serious cost to Caenorhabditis as previously surmised for other Serratia.

Results: A fecundity table of Caenorhabditis briggsae KT0001 fed on S. marcescens SCBI and the control fed on E. coli OP50 is presented. We found no significant difference in survivorship or total fecundity between the $S$. marcescens SCBI fed and E. coli OP50 fed Caenorhabditis briggsae KT0001. Only the mean onset of reproduction was significantly different between the two groups with E. coli fed C. briggsae maturing earlier (2.12 days) than those fed on Serratia (2.42 days).

Conclusion: S. marcescens SCBI is not highly pathogenic to C. briggsae KT0001 indicating that the entomopathogenicity reported for this association may be beneficial for both the nematode and bacteria. In light of the fact that hitherto conducted experimental tests conform to widely held view that Serratia are highly pathogenic to Caenorhabditis, the absence of a high fitness cost for C. briggsae we report here may indicate that this entomopathogenic association is non-transient suggesting nematode/bacterial associations in the wild may vary greatly. Consequently, broad generalizations about nematode/bacterial associations should be interpreted with care.
\end{abstract}

Keywords: Caenorhabditis briggsae, Serratia, Symbiosis, Fitness, Nematode-bacterial associations

\section{Background}

Nematode-bacterial associations have proven to be complex but our knowledge of their natural occurrence is limited. Two well-studied cases of nematode-bacterial associations are those of entomopathogenic nematodes and the case of Wolbachia and filarial worms [1]. Nematodes in these associations are considered obligate animal parasites. These studies demonstrated that bacterial associations could give the nematodes an advantage in ensuring the availability of food and the survival of the nematode species, and could even impact developmental processes of the host. Despite extensive studies on these

\footnotetext{
* Correspondence: Eyualem@Gmail.com

Department of Biology and Marine Environmental Science, Elizabeth City State University, Weeksville Road, Elizabeth City, NC 27909, USA
}

well-characterized nematode-bacterial associations, there is very little data on bacteria associated with free-living nematodes. Despite extensive research, our understanding of the ecology of Caenorhabditis in its natural settings is little explored [2]. For example, a recent study has changed the long-standing view that Caenorhabditis are inhabitants of organic rich soil environment to one where they are considered "fruit-worms" [3].

Bacterial associations of Caenorhabditis can vary vastly: they may be mutualistic, parasitic, or may be commensal where worms serve as vectors of pathogenic bacteria as in the case of C. elegans and Salmonella [4]. Pseudomonas strain DSS73 has been shown to associate mutually with $C$. elegans, increasing their survival in complex multispecies environments [5].
C Biomed Central

(c) 2012 Lancaster et al.; licensee BioMed Central Ltd. This is an Open Access article distributed under the terms of the Creative Commons Attribution License (http://creativecommons.org/licenses/by/2.0), which permits unrestricted use, distribution, and reproduction in any medium, provided the original work is properly cited. 
Although Caenorhabditis has long been considered to maintain necromenic associations with invertebrates [6], a recent report demonstrated, in laboratory experimental setting, a more active killing ability than the usual necromeny where an C. briggsae/Serratia marcescens association was shown to kill Galleria [7].

Serratia marcescens is a cosmopolitan bacterium widely isolated from soil, water, plants and insects, and exhibits pathogenic or saprophytic characteristics [8]. Its opportunistic pathogenicity in humans is also well recognized. Three recent studies have reported the association of Serratia with nematodes $[7,9,10]$. Those nematodes were isolated using standard Galleria traps and in all the three cases the association afforded the ability to kill the insect in laboratory setting which was mutually beneficial to the nematodes and bacteria. These laboratory associations are tripartite and complex involving the nematode that goes into the host insect, and symbiotically associated bacteria that kills the insect and in the process serves as food and creates a favorable environment for the nematodes to reproduce and complete their life cycle. Symbiosis, in biological context, is a broad term that represents long term associations between different biological species and could be one of the three main types: mutualism, commensalism, and parasitism.

Pathogenic bacteria are related to increased mortality, and reduced fecundity [11-13]. On the other hand, within the specific association of Caenorhabditis with Serratia marcescens, experimental tests of pathogenicity of the bacteria towards Caenorhabditis were shown to be strain-specific. Serratia marcescens Db10, for example, is known to kill Caenorhabditis [11,13], but $S$. marcescens SCBI did not kill the worms, instead it afforded them insect killing ability [7]. Given that Serratia is pathogenic to Caenorhabditis in experimental settings, investigating the cost of this relationship is relevant to a better understanding of the association and its historical progress. Also, it has been shown that the progeny count of C. elegans improved by $58 \%$ when fed live bacteria rather than feeding on dead bacteria [14] indicating that food quality impacts fitness in Caenorhabditis. As fitness is a key ecological parameter in measuring the success of any organism, and can be measured using reproductive rate, the objective of this research was 1) to evaluate if feeding on S. marcescens SCBI has a fitness cost for C. briggsae KT0001 and, 2) to estimate life history characteristics of the tropical strain $-C$. briggsae KT0001 - under laboratory conditions.

\section{Results}

\section{Survivorship}

Juvenile mortality was not observed in either the $E$. coli OP50 or S. marcescens SCBI fed C. briggsae, with all 88 juveniles surviving to maturity. Most of the reproductive output was complete by day 5 for both groups, and the survival rate for each group at that time was $85 \%$ for the E. coli OP50 fed population and $88 \%$ for the S. marcescens SCBI fed population. Both $S$. marcescens SCBI fed and E. coli OP50 fed populations of C. briggsae exhibited Type I survivorship curve (Figure 1) typical for the species, with most surviving until near end of life span. We found no significant difference in survivorship between the two groups of C. briggsae (log rank test, Chi sq $=0.4$, $\mathrm{p}=0.543)$ : median survival rate $\left(\mathrm{TL}_{50}\right)$ was 9 days. Average lifespan was $9.1 \pm 2.8$ days with a maximum lifespan of 14 days for the E. coli OP50 group compared to an average lifespan of $9.4 \pm 2.9$ days and maximum lifespan of 15 days in the $S$. marcescens SCBI group.

\section{Reproduction}

Reproduction was observed over a period of 15 days (day 0-14) with 9,385 offspring counted for all 88 individuals. Onset of reproduction was significantly different $(\mathrm{p}<0.05)$ with mean onset of reproduction at 2.12 days for the $E$. coli OP50 fed population and at 2.42 days for the $S$. marcescens SCBI fed population. A comparison of fecundity of C. briggsae fed on E. coli OP50 and fed on S. marcescens SCBI is shown in Figure 2. Fecundity was most pronounced between days 2 and 5, with day 4 marking the peak for both groups. Maximum age-specific fecundity peaked at a mean of 38 offspring/survivor for E. coli OP50 fed population and 40 offspring/survivor for $S$. marcescens SCBI fed population (Table 1). This difference was not statistically significant $(p=0.222)$.

We plotted total number of produced eggs against total lifetime (Figure 2) as suggested by Davies and Hart [14] and Muschiol et al. [15], to explore whether the two

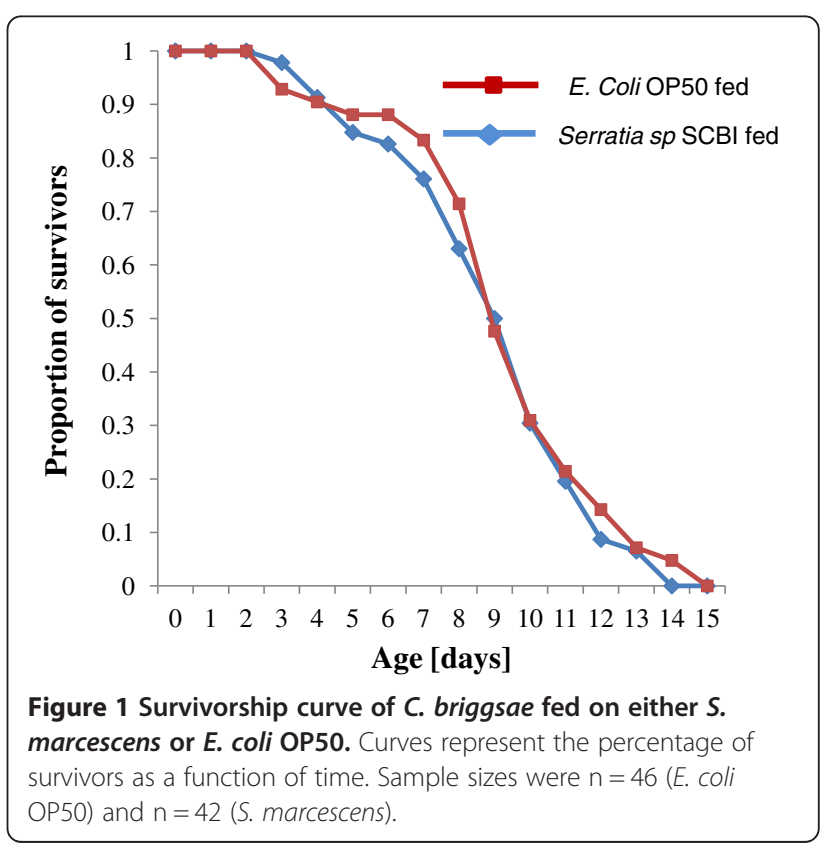




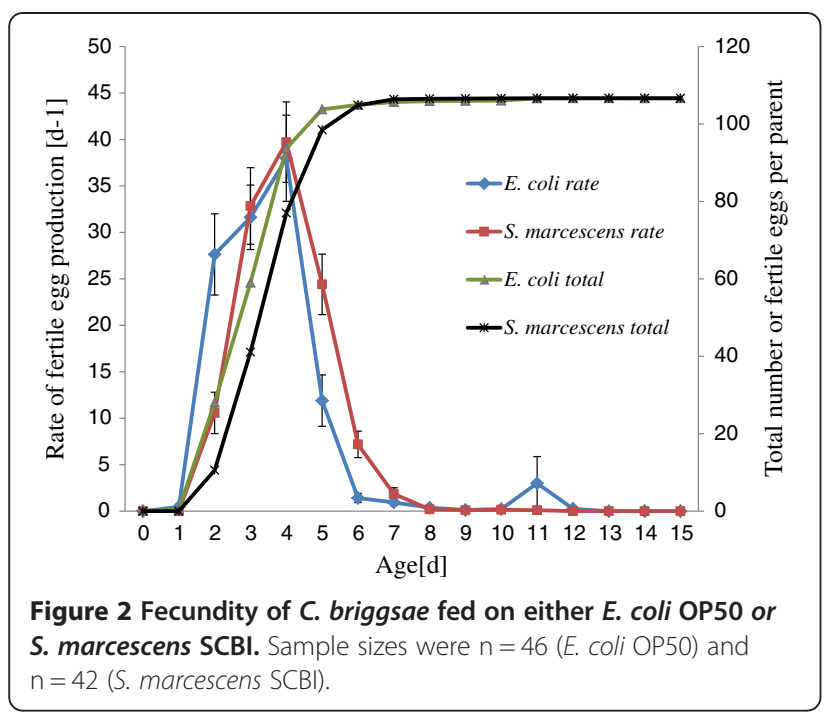

estimates are related. Spearman's rho was weak but significant in both groups $\left(E\right.$. coli OP50: $\mathrm{r}_{\mathrm{s}}=0.45, \mathrm{p}<0.01$; $S$. marcescens SCBI: $\left.\mathrm{r}_{\mathrm{s}}=0.43, \mathrm{p}<0.01\right)$.

The fecundity schedule of $C$. briggsae KT0001 is given in Table 1 . The sum of age-specific fecundity produced total fertility rates of 116 for the E. coli OP50 fed group and 117 for the $S$. marcescens SCBI fed group with net reproductive rates $\left(R_{0}\right)$ of 107 for both groups (Table 1 ). The minute discrepancies are due to the minutia difference in age-specific mortality.
Cohort generation time $\left(\mathrm{T}_{\mathrm{C}}\right)$ and intrinsic rate of natural increase $\left(\mathrm{r}_{\mathrm{m}}\right)$ differed slightly between the two groups with the E. coli OP50 fed C. briggsae KT0001 having a cohort generation time $\left(\mathrm{T}_{\mathrm{C}}\right)$ of 3.372 days and an intrinsic rate of natural increase $\left(\mathrm{r}_{\mathrm{m}}\right)$ of 1.385 ; and the $S$. marcescens SCBI fed C. briggsae having a cohort generation time $\left(\mathrm{T}_{\mathrm{C}}\right)$ of 3.892 days and an intrinsic rate of natural increase $\left(\mathrm{r}_{\mathrm{m}}\right)$ of 1.200. Population doubling times for C. briggsae KT0001 were calculated to be 12.0 hours for the E. coli OP50 fed group and 13.9 hours for the $S$. marcescens SCBI group. This is in comparison to known C. elegans populations doubling times [15] of 11.4 hrs (N2) and 12.1 hrs (MY6) when fed E. coli OP50 at $20 \pm 1^{\circ} \mathrm{C}$.

\section{Discussion}

The relationship between Caenorhabditis and S. marcescens has been shown to be strain and genotype-specific in lab experimental studies. For example, S. marcescens Sma13 is more virulent than S. marcescens ATCC274 to C. elegans MY10, but these results are contrary to what is reported for C. elegans MY20. C. elegans MY15 is also unique, with higher susceptibility to $S$. marcescens ATCC274 than to S. marcescens Db11, since most other C. elegans strains are more susceptible to Db11. It is not known if such strain- and genotype-specific relationships exist under natural conditions [16]. However, the isolation of S. marcescens SCBI from C. briggsae KT0001 [7]

Table 1 Life table and fecundity schedule of C. briggsae fed on E. coli OP50 or S. marcescens SCBI

\begin{tabular}{|c|c|c|c|c|c|c|c|c|c|c|}
\hline \multirow[b]{2}{*}{$\underline{x}$} & \multicolumn{5}{|c|}{ E. coli OP50 } & \multicolumn{5}{|c|}{ S. marcescens SCBI } \\
\hline & $\mathrm{n}_{\mathrm{x}}$ & $I_{x}$ & $m_{x}$ & $\mathrm{I}_{\mathrm{x}} \mathrm{m}_{\mathrm{x}}$ & $\mathrm{xl}_{\mathrm{x}} \mathrm{m}_{\mathrm{x}}$ & $n_{x}$ & $I_{x}$ & $m_{x}$ & $\mathrm{I}_{\mathrm{x}} \mathrm{m}_{\mathrm{x}}$ & $x l_{x} m_{x}$ \\
\hline 0.00 & 46.00 & 1.00 & 0.00 & 0.00 & 0.00 & 42.00 & 1.00 & 0.00 & 0.00 & 0.00 \\
\hline 1.00 & 46.00 & 1.00 & 0.46 & 0.46 & 0.46 & 42.00 & 1.00 & 0.00 & 0.00 & 0.00 \\
\hline 2.00 & 46.00 & 1.00 & 27.63 & 27.63 & 55.26 & 42.00 & 1.00 & 10.57 & 10.57 & 21.14 \\
\hline 3.00 & 45.00 & 0.98 & 31.62 & 30.94 & 92.81 & 39.00 & 0.93 & 32.85 & 30.50 & 91.50 \\
\hline 4.00 & 42.00 & 0.91 & 37.98 & 34.67 & 138.69 & 38.00 & 0.90 & 39.71 & 35.93 & 143.72 \\
\hline 5.00 & 39.00 & 0.85 & 11.90 & 10.09 & 50.43 & 37.00 & 0.88 & 24.41 & 21.50 & 107.50 \\
\hline 6.00 & 38.00 & 0.83 & 1.42 & 1.17 & 7.04 & 37.00 & 0.88 & 7.19 & 6.33 & 38.00 \\
\hline 7.00 & 35.00 & 0.76 & 0.94 & 0.72 & 5.02 & 35.00 & 0.83 & 1.86 & 1.55 & 10.83 \\
\hline 8.00 & 29.00 & 0.63 & 0.38 & 0.24 & 1.91 & 30.00 & 0.71 & 0.20 & 0.14 & 1.14 \\
\hline 9.00 & 23.00 & 0.50 & 0.13 & 0.07 & 0.59 & 20.00 & 0.48 & 0.10 & 0.05 & 0.43 \\
\hline 10.00 & 14.00 & 0.30 & 0.21 & 0.07 & 0.65 & 13.00 & 0.31 & 0.15 & 0.05 & 0.48 \\
\hline 11.00 & 9.00 & 0.20 & 3.00 & 0.59 & 6.46 & 9.00 & 0.21 & 0.11 & 0.02 & 0.26 \\
\hline 12.00 & 4.00 & 0.09 & 0.25 & 0.02 & 0.26 & 6.00 & 0.14 & 0.00 & 0.00 & 0.00 \\
\hline 13.00 & 3.00 & 0.07 & 0.00 & 0.00 & 0.00 & 3.00 & 0.07 & 0.00 & 0.00 & 0.00 \\
\hline 14.00 & 0.00 & 0.00 & 0.00 & 0.00 & 0.00 & 2.00 & 0.05 & 0.00 & 0.00 & 0.00 \\
\hline 15.00 & 0.00 & 0.00 & 0.00 & 0.00 & 0.00 & 0.00 & 0.00 & 0.00 & 0.00 & 0.00 \\
\hline$\sum$ & & & 115.92 & 106.65 & 359.58 & & & 117.14 & 106.65 & 415.01 \\
\hline
\end{tabular}

The fixed time interval, $x=$ age in days; $n_{x}=$ number of surviving individuals; $\mathrm{I}_{\mathrm{x}}=$ proportion of survivors remaining; $\mathrm{m}_{\mathrm{x}}=$ age-specific fecundity; $\sum \mathrm{m}_{\mathrm{x}}=$ total fertility rate (TFR); $\sum \mathrm{I}_{\mathrm{x}} \mathrm{m}_{\mathrm{x}}=$ net reproductive rate $\left(\mathrm{R}_{0}\right)$. 
in the framework of exploring nematode-bacterial associations, enabled us conduct our current study and the results give strong support to co- evolutionary interactions as was suggested by Schulenburg and Ewbank [16].

\section{Survivorship}

Survivorship is known to be markedly reduced for Caenorhabditis fed on pathogenic bacteria when compared to those fed on E. coli OP50 control [11,12,16-23]. This has been repeatedly shown on various strains of $C$. elegans with $S$. marcescens [11,16,18-20]. Sifri et al. [20] surveyed various survival rates for $C$. elegans fed on $S$. marcescens and found median survival rates $\left(\mathrm{TL}_{50}\right)$ of 2-6 days; similar results were observed $\left(\mathrm{TL}_{50}=4-5 \mathrm{~d}\right)$ by Pradel et al. [19] using two different strains of $S$. marcescens. These results differ greatly from our current results with our $\mathrm{TL}_{50}$ of 9 days for both groups of C. briggsae KT0001. The starkly similar survivorship curves of our C. briggsae grown on $S$. marcescens SCBI and E. coli OP50 may provide a strong indication that nematode-bacterial association in general and Caenorhabditis/S. marcescens relationships in particular, in the wild, may differ greatly from our current understanding based solely on laboratory experimental interactions.

\section{Reproduction}

Fecundity has been shown to be species specific in Caenorhabditis in the context of interactions with pathogenic bacteria. Rae et al. [23] showed a significant reduction in fecundity associated with high mortality before and during peak reproduction, while Baeriswyl et al. [12] showed no significant difference in fecundity in relation to various strains of $E$. coli, had an earlier onset of reproduction and less mortality prior to peak reproduction. This suggests that fecundity is reduced in Caenorhabditis by highly pathogenic bacteria due to age-specific morbidity and mortality. Our results showed no significant difference between net reproductive rate or total fertility which, in light of Rae et al. [23], precludes the C. briggsae KT0001/S. marcescens SCBI relationship from the league of the highly pathogenic relationships reported elsewhere. Differences in mean onset of reproduction were significant (2.12 days for the E. coli OP50 fed group and 2.42 days for the $S$. marcescens SCBI fed group). This shift reduced overall fitness by increasing cohort generation time $\left(\mathrm{T}_{\mathrm{C}}\right)$ and reducing intrinsic rate of natural increase $\left(r_{m}\right)$. This shows that although the relationship shows a marked difference from entirely pathogenic forms, it is not entirely mutualistic either at a level comparable to what we observe in archetypical entomopathogenic nematodes and their symbionts. Life history theory suggests this shift may be due to an investment in defense mechanisms [24]. The maintenance of net reproductive rate and total fertility, despite investments in defense mechanisms, supports long term co-evolutionary interactions consistent with a nontransient relationship.

Symbiotic relationships are often complex and range from parasitic to mutualistic. The fitness benefits of microbial symbionts to the symbiont partner is recently shown to be context dependent [25] where environmental factors may affect rapid shifts between mutualism and parasitism [26]. Weeks et al. [27] showed that such evolutionary shifts in nature can be achieved within a relatively short period of time. Moreover, the theoretical divide between parasitism and mutualism has blurred over the last decade in that mutualists are selected to minimize their costly contributions while maximizing their benefits from the relationship - a processes resembling the 'antagonistic arms race' model except here the symbiont pair are selected to exploit each other while minimizing loss on their side [28]. Sachs et al. [28] argues that "transitions to host association might be constrained only by access to and compatibility with horizontally transferred loci that engender host-association traits". Previous reports of some Serratia marcescens as pathogenic to Caenorhabditis species, and recent findings that many species of Serratia are symbiotically associated with invertebrate hosts and our findings of a Serratia marcescens SCBI associated with $C$. briggsae KT0001 that experimentally was able to kill Galleria are in support of an unexplored diversity of Serratia within an umbrella species name - Serratia marcescens. In addition, Sachs' et al. [28] predictions coupled with the fact that nematodes and bacteria are two speciesrich and ancient groups $[29,30]$ imply that expecting to find a diverse array of hitherto undiscovered nematodebacterial associations is not unreasonable.

\section{Conclusion}

S. marcescens SCBI does not affect the longevity of $C$. briggsae KT0001. As a result, the association between the two is likely to impose a minimal reproductive cost to the nematode, an indication that although such associations between Caenorhabditis and Serratia have been widely reported to affect the fitness of the nematode through bacterial pathogenicity, our findings show the C. briggsae KT0001/S. marcescens SCBI association to be an exception to the rule.

\section{Methods}

\section{Culture maintenance}

We used C. briggsae KT0001 from the original collection at the Hubbard Center for Genome Studies, University of New Hampshire. C. briggsae were cultivated from frozen stocks, and were maintained on Nematode Growth Media (NGM) by transferring a number of adults every week onto a NGM plate with fresh food [31,32]. The primarily goal of the experiment was to test the implications of the two types of bacterial food sources, $S$. 
marcescens SCBI and E. coli OP50, on nematode reproductive potential. As a result, nematodes were maintained on two sets of cultures: one seeded with $20 \mu \mathrm{L} \mathrm{E}$. coli OP50 starting from the initial thawing to the completion of the experiment and the second on S. marcescens SCBI.

Nematode Growth Gelrite (NGG) media was prepared following the protocol described by Muschiol \& Traunspurger [33]. NGG was made by replacing agar with $1.5 \mathrm{~g}$ of gellan gum in NGM. The viscosity of this media allowed individuals to move freely throughout the media whilst preventing bacteria from settling. Its transparency also allowed easy transfer of individuals and counting of juveniles.

\section{Food preparation}

E. coli OP50 and S. marcescens SCBI were inoculated into sterile LB broth and put on a shaker for 24 hours at $20^{\circ} \mathrm{C}$ to allow for cell growth. After $24 \mathrm{hrs}$, bacteria were concentrated to $10^{10}$ cells $/ \mathrm{mL}$ using an absorption $\left(\mathrm{OD}_{600}\right)$ vs. bacterial concentration curve [33].

\section{Experimental setup}

Our experimental setup closely followed that described by Muschiol and Traunspurger [15]. Sets of 24 well multiwell plates were used with $10 \mu \mathrm{L}$ mixture drops (i.e. $8 \mu \mathrm{L}$ of NGG with $2 \mu \mathrm{L}$ of bacterial food) added to the center of the lid of each well of the multi-well plate. The wells consisted of a $1 \mathrm{~mL}$ mix of cellulose and sterile water in order to maintain humidity and prevent the drops from drying out. A synchronous juvenile worm was added to each drop. Every 24 hours we transferred each worm to a new NGG drop until all died. All NGG drops were kept at $20^{\circ} \mathrm{C}$ in the environmental chamber for an additional 24 hours after the individual was transferred or died. This $24 \mathrm{hr}$ time allowed eggs to hatch. We counted only juveniles as an indicator of fertile eggs. Twenty-four hours after transfer, juveniles were stained with $10 \mu \mathrm{L}$ of rose Bengal, squashed with a $30 \mathrm{~mm}$ round cover slip, and counted under a 40X magnification dissecting microscope (Olympus SZX10 Stereomicroscope).

\section{Data processing}

Life tables and fecundity schedules (Table 1) were constructed to find cohort generation time $\left(\mathrm{T}_{\mathrm{C}}\right)$, intrinsic rate of natural increase $\left(\mathrm{r}_{\mathrm{m}}\right)$, and population doubling time (PDT) using the following equations:

$$
\begin{aligned}
& \text { TFR }=\sum m_{\times} \\
& R_{0}=\sum_{\times} m_{\times} \\
& T_{c}=\sum x_{x} m_{x} / R_{0}
\end{aligned}
$$

$$
\begin{aligned}
& r_{m}=\ln R_{0} / T_{c} \\
& \mathrm{PDT}=\ln 2 / r_{m}
\end{aligned}
$$

$\mathrm{x}=$ time $[\mathrm{d}]$

$l_{\mathrm{x}}=$ age specific survival probability

$\mathrm{m}_{\mathrm{x}}=$ age specific fecundity

TFR - total fertility rate

$\mathrm{R}_{0}=$ net reproductive rate

$\mathrm{T}_{\mathrm{C}}=$ cohort generation time

$\mathrm{r}_{\mathrm{m}}=$ approximate intrinsic rate of natural increase

$\mathrm{PDT}=$ population doubling time

The net reproductive rate $\left(R_{0}\right)$ is the average number of offspring from an individual in a lifetime, and dependent on age specific mortality. Cohort generation time $\left(\mathrm{T}_{\mathrm{C}}\right)$ is the mean age of a female cohort at reproduction. The intrinsic rate of natural increase $\left(r_{m}\right)$ is a measure of growth rate and fitness in a population of stable age distribution, and unlimited growth [15].

Statistical analysis was carried out using Microsoft Excel (2007) or manually. Unpaired data was compared using student's $T$-test. Survivorship was compared using a log-rank test, and total number of offspring vs. total lifetime was correlated using Spearman's rho.

\section{Competing interests}

The authors declare that they have no competing interests.

\section{Authors' contributions}

$J D L$ and BM carried out the experiment and drafted the manuscript. JDL analyzed the data. EA conceived of the study, designed the experiment, coordinated and supervised the work and wrote the manuscript in its final form. All authors read and approved the final manuscript.

\section{Acknowledgements}

This work was supported in part by the US Army Research Laboratory and US Army Research Office under Contract number W911NF-08-1-0402, and US National Science Foundation Award Number 0808632. We thank Dr. Roberto Frontera-Suau, Elizabeth City State University, for allowing us to use equipment in his lab.

Received: 4 September 2012 Accepted: 18 December 2012 Published: 20 December 2012

\section{References}

1. Landmann F, Voronin D, Sullivan W, Taylor MJ: Anti-filarial activity of antibiotic therapy is due to extensive apoptosis after Wolbachia depletion from filarial nematodes. PLOS Pathog 2011, 7(11):1-11.

2. Caswell-Chen EP, Chen J, Lewis EE, Douhan GW, Nadler SA, Carey JR: Revising the standard wisdom of $C$. Elegans natural history: ecology of longevity. Sci Aging Knowl Environ 2005, 40:pe30.

3. Kointke K, Felix M, Ailion M, Rockman M, Braendle C, Pénigault J, Fitch D: A phylogeny and molecular barcodes for Caenorhabditis, with numerous new species from rotting fruits. BMC Evol Biol 2011, 339(11):1471-2148.

4. Lacharme-Lora L, Perkins SE, Humphrey TJ, Hudson PJ, Salisbury V: Use of bioluminescent bacterial biosensors to investigate the role of free-living helminths as reservoirs and vectors of Salmonella. Environ Microbiol Rep 2009, 1(3):198-207.

5. Bjørnlund L, Rønn R, Péchy-Tarr M, Maurhofer M, Keel C, Nybroe O: Functional GacS in Pseudomonas DSS73 prevents digestion by Caenorhabditis elegans and protects the nematode from killer flagellates. ISME J: Multidisciplinary Journal of Microbial Ecology 2009, 3(7):770-779. 
6. Ali S, Pervez R, Andrabi R, Sharma R, Verma W: Oscheius amsactae n. sp. (Nematoda: Rhabditida), a necromenic associate of red-hairy caterpillar, Amsacta moori (Lepidoptera: Arctiidae) from Kanpur district, India. Arch Phytopathology Plant Protect 2011, 44(9):871-881.

7. Abebe E, Jumba M, Bonner K, Gray V, Morris K, Thomas W: An entomopathogenic Caenorhabditis briggsae. J Exp Biol 2010, 213(18):3223-3229.

8. Ovcharenko LP, Voznyuk TM, Zaetz IE, Potopalsky Al, Reva O, Kozyrovska NO: A mobile genetic element in Serratia marcescens, a causative agent of onion disease. Biopolym Cell 2010, 26(4):279-285.

9. Zhang C-X, Yang S-Y, Xu M-X, Sun J, Liu H, Liu J-R, Liu H, Kan F, Sun J, Lai R, Zhang K-Y: Serratia nematodiphila sp. nov., associated symbiotically with the entomopathogenic nematode Heterorhabditidoides chongmingensis (Rhabditida: Rhabditidae). Int J Syst Evol Microbiol 2000, 59:1603-1608.

10. Torres-Barragan A, Suazo A, Buhler W, Cardoza Y: Studies on the entomopathogenicity and bacterial associates of the nematode Oscheius carolinensis. Biol Control 2011, 59(2):123-129.

11. Murdoch SL, Trunk K, English G, Fritsch MJ, Pourkarimi E, Coulthurst SJ: The opportunistic pathogen Serratia marcescens utilizes type VI secretion to target bacterial competitors. J Bacterio/ 2011, 193(21):6057-6069.

12. Baeriswyl S, Médéric D, Mosser T, Leroy M, Manière X, Taddei F, Matic I: Modulation of aging profiles in isogenic populations of Caenorhabditis elegans by bacteria causing different extrinsic mortality rates. Biogerontology 2010, 11:53-65.

13. Mallo GV, Kurz CL, Couillault C, Pujol N, Granjeaud S, Kohara Y, Ewbank JJ: Inducible antibacterial defence system in C.elegans. Curr Biol 2002, 12:1209-1214.

14. Davies KG, Hart JE: Fecundity and lifespan manipulations in Caenorhabditis elegans using exogenous peptides. Nematology 2008, 10(1):103-112

15. Muschiol D, Schroeder F, Traunspurger W: Life cycle and population growth rate of Caenorhabditis elegans studied by a new method. BMC Ecol 2009, 9:14.

16. Schulenberg $\mathrm{H}$, Ewbank J: Diversity and specificity in the interaction between Caenorhabditis elegans and the pathogen Serratia marcescens. BMC Evol Biol 2004, 4:49.

17. Lee S-H, Ooi S-K, Mahadi NM, Tan M-W, Nathan S: Complete killing of caenorhabditis elegans by Burkholderia pseudomallei is dependent on prolonged direct association with the viable pathogen. PLoS One 2011, 6(3):e16707.

18. Ewbank J: Tackling both sides of the host-pathogen equation with Caenorhabditis elegans. Microbes Infect 2002, 4(2):247-256.

19. Pradel E, Zhang Y, Pujol N, Matsuyama T, Bargmann C, Ewbank J: Detection and avoidance of a natural product from the pathogenic bacterium Serratia marcescens by Caenorhabditis elegans. PNAS 2006, 104(7):2295-2300.

20. Sifri C, Begun J, Ausubel F: The worm has turned - microbial virulence modeled in Caenorhabditis elegans. Trends Microbiol 2005, 13(3):119-127.

21. Portal-Celhay C, Bradley E, Blaser M: Control of intestinal bacterial proliferation in regulation of lifespan in Caenorhabditis elegans. BMC Microbiol 2012, 12:49.

22. Couillault C, Ewbank J: Diverse bacteria are pathogens of Caenorhabditis elegans. Infect Immun 2002, 70(8):4705-4707.

23. Rae R, latsenko I, Witte $H$, Sommer R: A subset of naturally isolated Bacillus strains show extreme virulence to the free-living nematodes Caenorhabditis elegans and Pristionchus pacificus. Environ Microbiol 2010, 12(11):3007-3021.

24. Doroszuk A, Wojewodzic M, Kammenga J: Rapid adaptive divergence of life-history traits in response to abiotic stress within a natural population of a parthenogenetic nematode. Proc Biol Sci 2006, 273:2611-2618.

25. Heath KD, Tiffin P: Context dependence in the coevolution of plant and rhizobial mutualists. Proc Bio/ Sci 2007, 274:1905-1912.

26. Sachs JL, Simms EL: Pathways to mutualism breakdown. Trends Ecol Evol 2006, 21:585-592.

27. Weeks R, Turelli M, Harcombe WR, Reynolds KT, Hoffman AA: From parasite to mutualist: rapid evolution of Wolbachia in natural populations of drosophila. PLoS Biol 2007, 5(5):e114.

28. Sachs $J$, Essenberg CJ, Turcotte MM: New paradigms for the evolution of beneficial infections. Trends Ecol Evol 2011, 26:202-209. doi:10.1016/j.tree.2011.01.010 (2011) 1-8.
29. Meldal BHM, Debenham NJ, De Ley P, De Ley IT, Vanfleteren JR, Vierstraete AR, Vierstraete AR, Bert W, Borgonie G, Moens T, Tyler PA, Austen MC, Blaxter ML, Rogers AD, Lambshead PJD: An improved molecular phylogeny of the Nematoda with special emphasis on marine taxa. Mol Phylogenet Evol 2007, 42:622-636.

30. Achtman $M$, Wagner $M$ : Microbial diversity and the genetic nature of microbial species. Nature Rev Microbiol 2008, 6(6):431-440.

31. Brenner S: The genetics of Caenorhabditis elegans. Genetics 1974, 77:71-94.

32. Stiernagle T: Maintenance of C. elegans. In The C elegans Research Community, Wormbook. 2006.

33. Muschiol D, Traunspurger W: Life cycle and calculation of the intrinsic rate of natural increase of two bacterivorous nematodes, Panagrolaimus sp. and Poikilolaimus sp. from chemoautotrophic Movile Cave, Romania. Nematology 2007, 9(2):271-284.

\section{doi:10.1186/1756-0500-5-688}

Cite this article as: Lancaster et al:: Effect of the bacterium Serratia marcescens SCBI on the longevity and reproduction of the nematode Caenorhabditis briggsae KT0001. BMC Research Notes 2012 5:688.

\section{Submit your next manuscript to BioMed Central and take full advantage of:}

- Convenient online submission

- Thorough peer review

- No space constraints or color figure charges

- Immediate publication on acceptance

- Inclusion in PubMed, CAS, Scopus and Google Scholar

- Research which is freely available for redistribution 